\section{Primum non nocere}

\section{Erika Mendoza}

Venenpraxis, Wunstorf, Germany

\section{Dear Editor,}

Thank you for the editorial pointing out the possibility of sparing saphenous veins in Phlebology. ${ }^{1}$ You are right pointing out, that the innovation in Phlebology goes ahead and looking at the last 20 years one could think, that everything might be possible to deal with varicose veins.

Of course, surgical ablation of great saphenous veins (GSV) has the longest history and so the procedure is carved in stone in many National Health Services (NHS) as the Gold Standard (so still in Germany!!) and in many brains of lots of honorable chiefs of department. But there is another point to be taken into consideration: Other than in Spain and Italy, where Department chiefs and surgeons are employed by the NHS and earn their money independently of the sales - in lots of countries the Health Professionals' income depends on their performance. The higher the income for a procedure, the higher the personal financial benefit. In poorer countries foam sclerotherapy is the best option. In high sophisticated places, the more the cost, the better the treatment, the better the income. Endoluminal heat treatments were introduced as a way to do stripping without a knife. So the idea from the very beginning included heating the complete refluxive segment of the saphenous vein.

In the recently published study, CHIVA with endoluminal procedures: LASER versus $V N U S,{ }^{2}$ it could be demonstrated, that the short term results of CHIVA with both methods (LASER or VNUS Closurefast) were identical and both methods showed no statistical differences to another cohort of surgically treated CHIVA patients: 104 patients were investigated before and 3-6 months after the treatment of GSV with CHIVA strategy using enoluminal heat techniques to close the groin segment [VNUS Closurefast or LASER (1470 nm, Intros radial)]. General data (age, sex, BMI) and phlebological data (QoL as reflected in VCSS, clinics as C(CEAP), diameters of GSV at the groin and proximal thigh, as well as diameters of the common femoral vein were not different among both groups. As a result, we found a significant reduction of diameters of GSV at proximal thigh from $6.5+/-1.6$ to $3.7+/-1.1$ and VFC from 15.2 $+/-2.3$ to $14.8+/-2.2$ were recorded, as well as reduction of clinical scores (VCSS from $5.6+/-3.1$ to $2.2+/-2$ and C(CEAP) from $3.2+/-1$ to $2.1+/-1.1$. Results are comparable to those achieved after surgical crossectomy and published in other series.

In this publication, we do not only open CHIVA to other techniques, but we also show that even applying high technology (endoluminal heat and possibly glue) it is not necessary to sacrifice the complete length of the saphenous vein.

If those patients with reflux in GSV but competentterminal valve would be treated withouth high ligation but with CHIVA (flush ligation of the tributary) or Müller/ASVAL and in those with incompetent terminal valve only a short segment would be closed with endoluminal devices,
Correspondence: Erika Mendoza, Venenpraxis, Speckenstrasse 10, 31515 Wunstorf, Germany. Tel.: 05031.912781.

E-mail: erika.mendoza@t-online.de

Conflict of interest: the author declares no potential conflict of interest.

Received for publication: 13 February 2017. Accepted for publication: 27 February 2017.

This work is licensed under a Creative Commons Attribution 4.0 License (by-nc 4.0).

CCopyright E. Mendoza, 2017

Licensee PAGEPress, Italy

Veins and Lymphatics 2017; 6:6646

doi:10.4081/vl.2017.6646

we could spare far more than $50 \%$ of saphenous veins. As a Bypass? As a drainage path? As an option to treat the vein in the future - when possibly even more gentle techniques are available? As a tribute to our maximal objective in medicine: Primum non nocere?

\section{References}

1. Zamboni P. 2016: The year of Phlebological Olympic Games. Veins and Lymphatics 2016;5:6249.

2. Mendoza E. CHIVA performed with endoluminal heat technique: laser versus VNUS Cross treatment of the great sapenous vein. Phlebologie 2017;46:5-12. 